British Journal of Nutrition (2021), 125, 203-211

doi: $10.1017 /$ S0007114520002640

(C) The Author(s), 2020. Published by Cambridge University Press on behalf of The Nutrition Society. This is an Open Access article, distributed under the terms of the Creative Commons Attribution licence (http://creativecommons.org/licenses/by/4.0/), which permits unrestricted re-use, distribution, and reproduction in any medium, provided the original work is properly cited.

\title{
Salt taste perception and blood pressure levels in population-based samples: the Circulatory Risk in Communities Study (CIRCS)
}

\author{
Asako Kudo ${ }^{1}$, Akihiko Kitamura ${ }^{1,2}$, Hironori Imano ${ }^{1}$, Renzhe Cui ${ }^{1}$, Mitsumasa Umesawa ${ }^{3,4}$,
} Kazumasa Yamagishi ${ }^{4}$, Tetsuya Ohira ${ }^{5}$, Isao Muraki ${ }^{1}$, Mina Hayama-Terada ${ }^{6}$, Masahiko Kiyama ${ }^{6}$ and Hiroyasu Iso ${ }^{1 *}$ for CIRCS Investigators $\dagger$

${ }^{1}$ Public Health, Department of Social Medicine, Osaka University Graduate School of Medicine, Osaka, Japan

${ }^{2}$ Research Team for Social Participation and Community Health, Tokyo Metropolitan Institution of Gerontology, Tokyo, Japan

${ }^{3}$ Department of Public Health, Dokkyo Medical University School of Medicine, Tochigi, Japan

${ }^{4}$ Department of Public Health Medicine, Faculty of Medicine, and Health Services Research and Development Center, University of Tsukuba, Ibaraki, Japan

${ }^{5}$ Department of Epidemiology, School of Medicine, Fukushima Medical University, Fukushima, Japan

${ }^{6}$ Osaka Center for Cancer and Cardiovascular Diseases Prevention, Osaka, Japan

(Submitted 3 April 2020 - Final revision received 18 June 2020 - Accepted 26 June 2020 - First published online 20 August 2020)

\section{Abstract}

To examine the associations of salt perception with salt intake and blood pressure levels in general populations, we performed a cross-sectional study in two communities where salt intake level is different, Akita and Osaka in Japan. Taste perception (detection for certain taste and recognition for salt taste) was determined using a Na-impregnated test strip for 1024 Akita and 1199 Osaka adults aged 30-74 years. The proportions of detection for $0 \cdot 1 \%$ salt were $61,62,79$, and $79 \%$ in Akita men, Osaka men, Akita women and Osaka women, respectively. The corresponding proportions of not recognising of $1.6 \%$ salt taste $(>1.6 \%)$ were $34,30,16$ and $21 \%$. Detection threshold was higher in Akita than in Osaka for women aged 60-74 years, and recognition threshold was lower in Akita than in Osaka for women aged 30-59 and 60-74 years. The high detection $(\geq 0.4 \%)$ and recognition $(>1.6 \%)$ thresholds of salt taste were associated with higher salt intake scores for Akita men aged 30-59 years, whose detection and recognition thresholds tended be positively associated with systolic and diastolic blood pressures (SBP and DBP) after adjustment for potential confounders. Among Akita elderly men, detection threshold tended to be positively associated with SBP and DBP, while among Akita middle-aged women, recognition threshold was associated with SBP. In conclusion, the high thresholds of salt perception were inversely associated with salt intake for Akita middle-aged men and with blood pressure levels for Akita middle-aged and elderly men and middle-aged women.

Key words: Salt taste: Perception: Blood pressure: Salt intake behaviour: Population-based studies

Hypertension is a major risk factor for CVD across the world. The prevalence of hypertension among adults was one-third of the total population in many countries including Japan ${ }^{(1,2)}$.

The prevention and control of hypertension have contributed to a substantial decline in stroke mortality in $\operatorname{Japan}^{(3)}$. Within Japan, however, there has been a regional difference in blood pressure levels and the incidence of stroke; levels were higher in northeastern Japan and lower in western Japan ${ }^{(4)}$, which was attributable in part to high salt intake. In Akita (northeastern Japan), mean daily salt intake among middle-aged men was $20 \mathrm{~g} / \mathrm{d}$ in 1969 and declined to $14 \mathrm{~g} / \mathrm{d}$ between 1980 and $1983^{(5)}$. According to the 2017 National Nutrition and Health Examination Survey, mean salt intake among adults aged $\geq 20$ years was $11.6 \mathrm{~g}$ for men and $9.6 \mathrm{~g}$ for women, which was still higher than in other regions of Japan ${ }^{(6)}$. The corresponding mean intake in 2017 was $9.9 \mathrm{~g}$ for men and $8.4 \mathrm{~g}$ for women in

Abbreviations: DBP, diastolic blood pressure; SBP, systolic blood pressure.

* Corresponding author: Dr Hiroyasu Iso, fax +81-6-6879-3919, email iso@pbhel.med.osaka-u.ac.jp

$\dagger$ The CIRCS Investigators are Takeo Okada, Mina Hayama-Terada, Shinichi Sato, Yuji Shimizu and Masahiko Kiyama, Osaka Center for Cancer and Cardiovascular Disease Prevention; Akihiko Kitamura, Hironori Imano, Renzhe Cui, Isao Muraki and Hiroyasu Iso, Osaka University; Kazumasa Yamagishi and Tomoko Sankai, University of Tsukuba; Isao Koyama and Masakazu Nakamura, National Cerebral and Cardiovascular Center; Masanori Nagao and Mitsumasa Umesawa, Dokkyo Medical University School of Medicine; Tetsuya Ohira, Fukushima Medical University; Koutatsu Maruyama and Isao Saito, Ehime University and Ai Ikeda and Takeshi Tanigawa, Jyuntendo University. 
Osaka, mid-western $\operatorname{Japan}^{(6)}$. Mean salt intakes in both Akita and Osaka are still higher than the recommended values for Japanese residents and far higher than the WHO recommendation $(5 \mathrm{~g})^{(7)}$.

Salt taste perception is a factor influencing salt intake $\mathrm{e}^{(8,9)}$. Previous cross-sectional studies with small sample sizes ( $n$ 40-90) showed that lower salt taste perception was associated with higher 24-h urine $\mathrm{Na}$ excretion $^{(8)}$ and higher salt intake ${ }^{(9)}$, and lower taste perception was associated with a higher prevalence of hypertension ${ }^{(9-13)}$, as indicated by increased systolic and diastolic blood pressure (SBP and DBP) levels ${ }^{(14,15)}$. A Japanese study of middle-aged men and women aged $\geq 40$ years using Na-impregnated test strips showed that impaired salt taste (high salt recognition threshold) was associated with a higher prevalence of hypertension among women and their husbands ${ }^{(16)}$. In a Japanese study of women aged 40-74 years, the high perception threshold ( $\geq 1.0 \%$ of salt) was associated with the masked hypertension $(\geq 135 /$ $85 \mathrm{mmHg})^{(17)}$.

Our a priori hypothesis is that Akita persons show lower salt taste perception (recognition and detection) than Osaka persons because of their habitual higher salt intakes. The low salt recognition and detection may be associated with salt intake behaviours and higher blood pressure levels. Such trends are observed similarly for both men and women of middle and elderly ages. We aimed to clarify the distributions of salt taste perception and its associations with salt intake behaviours and blood pressure levels among population-based samples in Akita and Osaka communities with different salt intake levels.

\section{Methods}

\section{Study population}

This cross-sectional study was conducted under a cohort study of the Circulatory Risk in Communities Study (CIRCS $)^{(18,19)}$. The surveyed populations were men and women aged $30-74$ years living in two communities - Ikawa town (a rural community in Akita Prefecture in northeastern Japan) and the MinamiTakayasu district in Yao City (a suburb community in Osaka Prefecture in mid-western Japan), both of which participated in the cardiovascular risk surveys in 2015 and 2016. A total of 1307 persons ( 524 men and 783 women) in Ikawa town (Akita) and 1760 persons ( 577 men and 1183 women) in the Minami-Takayasu district (Osaka) participated in the surveys. Among the survey participants, 1254 (504 men and 750 women) and 1388 (452 men and 936 women), respectively, gave consent to take the salt taste test.

We excluded 396 persons who recognised some taste on the no-Na strip (no salty taste): 222 (seventy-five men and 147 women) in Akita and 174 (fifty-two men and 122 women) in Osaka. Twenty-three persons had missing data in the questionnaire: eight (two men and six women) in Akita and fifteen (five men and ten women) in Osaka. Finally, we used the data of 1024 persons ( 427 men and 597 women) in Akita and 1199 subjects (395 men and 804 women) in Osaka for the analyses.

\section{Data collection}

Salt taste perception test. Our survey was conducted at room in early summer in Akita and in winter in Osaka. However, the room temperature was kept around $20^{\circ} \mathrm{C}$. Taste tests were conducted as a part of health checkups where about $70 \%$ of the participants are tested in the morning and about $30 \%$ in the afternoon.

Salt taste perception was determined with a salt-impregnated taste strip, Salsave (Advantech Toyo Co.) ${ }^{(20)}$, impregnated with sodium chloride at concentrations of $0,0 \cdot 6,0 \cdot 8,1 \cdot 0,1 \cdot 2,1.4$ and $1.6 \%$ with the extended lower concentrations of $0 \cdot 1,0.2$ and $0.4 \%$. To validate these concentrations, we measured them using a polarised Zeeman atomic absorption spectrophotometer (model ZA-330, Hitachi High-Technologies Corporation). One piece of strip was dipped in $50 \mathrm{ml}$ of distilled water for $48 \mathrm{~h}$, and the sample water was diluted appropriately and applied to measure $\mathrm{Na}$ concentrations ${ }^{(21)}$. We confirmed the validity of all $\mathrm{Na}$ concentrations in every lot used.

We performed salt taste tests twice on twenty-five persons aged 22-54 years (average age 34.2 years) at 1-3 months apart. The Spearman correlation coefficient for recognition threshold was $0.59(P=0.002)$. The correlation for detection threshold could not be estimated in valid because of the narrow range $(0.1$ or $0.2 \%)$ in the samples.

\section{Constitutional and behavioural factors}

We interviewed the subjects to determine whether they smoked, ate something and/or drank coffee or juice within $2 \mathrm{~h}$ before the test, and we asked if they were wearing dentures or had a stuffy/runny nose. We confirmed that these behaviours and symptoms were not related to salt taste perception, so we did not use these data for the analyses.

The detection threshold was defined as the lowest concentration at which the subject recognised change from a no-Na strip (no salty taste) to a Na-impregnated test strip, but the type of taste was not necessarily recognised. The recognition threshold was defined as the lowest concentration at which the subject recognised salty taste in two consecutive strips.

Before the taste test and during the test as needed, the subject's mouth was moisturised with distilled water. To assess the salty taste, the subject held the $0 \cdot 1 \%$ strip in the mouth for $3 \mathrm{~s}$ and repeated the procedure using the strips of the higher concentrations of sodium chloride. An interviewer asked the subject whether he or she experienced no taste, some taste, sweet taste, salty taste, sour taste or bitter taste. Strips with increasing salt concentrations were applied until the subjects replied 'salty taste' for two consecutive concentrations. When the subject replied 'some taste' once, it was defined as the detection threshold. When the subject replied 'salty taste,' the higher concentration strip was reapplied. The concentration was at which the subjects could properly report a 'salty taste' sense. The lower concentration was defined as the value of recognition threshold.

The measurement of arterial SBP and fifth-phase DBP was performed by well-trained physicians using standard mercury sphygmomanometers on the right arm of participants after a rest of 5 min while seated. A second measurement of blood pressure 
was performed when participants had high blood pressure (130 mmHg SBP or $85 \mathrm{mmHg}$ DBP) at the first measurement for the detection and follow-up of hypertensive subjects. In the present study, the data for the first blood pressure measurement were used for the analyses. Hypertension was defined as $\mathrm{SBP} \geq 140 \mathrm{mmHg}$ and/or DBP $\geq 90 \mathrm{mmHg}$ and/or medication use for hypertension. Height in stocking feet and weight in light clothing were measured, and BMI was calculated as weight $(\mathrm{kg}) /$ height $(\mathrm{m})^{2}$. Overweight was defined as BMI $\geq 25 \mathrm{~kg} / \mathrm{m}^{2}$. Diabetes was defined as HbA1c (National Glycohemoglobin Standardization Program) $\geq 6.5 \%$, and/or a serum glucose level of $\geq 126 \mathrm{mg} / \mathrm{dl}(7.0 \mathrm{mmol} / \mathrm{l})$ during fasting or $\geq 200 \mathrm{mg} / \mathrm{dl}(11 \cdot 1$ $\mathrm{mmol} / \mathrm{l}$ ) during non-fasting, and/or medication use for diabetes.

An interview was conducted to ascertain the smoking status, usual ethanol intake per week, dietary behaviours, eating behaviours and preference of taste. Smoking status was defined as never, former and current smoker. Ethanol intake status was defined as never, former or current drinker, and for current drinkers, we converted the usual ethanol intake of the Japanese unit 'go' into $23 \mathrm{~g}$ of ethanol per d. We asked about behaviours of the salty food intake using the questionnaire: 'Do you season all food salty?', 'Do you drink salty soup (miso-soup etc.) $\geq 2$ times per d?', 'Do you drink up noodle soup?', 'Do you eat salt-preserved food $\geq 3$ times per week?', 'Do you put salty soya or Western sauce before checking taste?', 'Do you eat salt-preserved pickles $\geq 2$ times per d?', Other eating behaviours were asked, such as 'the frequency of eating out $\geq 1$ time per week' and 'the frequency of eating delicatessen foods $\geq 1$ time per week'. The salt intake score was defined as counting the number of salty food intake behaviours ${ }^{(21)}$.

\section{Ethics, consent and permissions}

This study was conducted according to the guidelines laid down in the Declaration of Helsinki, and all procedures involving research study participants were approved by the Ethics Committee of Osaka University (no. 14285) and the Institutional Review Board of the Osaka Center for Cancer and Cardiovascular Disease Prevention (26-ethics-15). According to the Japanese ethics guidelines, we provided the ethical information on our study at the survey sites and opted out opportunities. Verbal informed consent was obtained from all subjects. The consent was obtained from the area representative (the 'mayor') after explaining the purpose of the study.

\section{Statistical analysis}

Characteristics of the study subjects were presented as mean values and standard deviations or proportions (\%). These characteristics were compared between Akita and Osaka using ANCOVA and the $\chi^{2}$ test.

The analysis for trends, salt intake score, SBP and DBP according to detection and recognition thresholds was conducted using the median of detection and recognition thresholds in each category. The detection threshold was categorised as the salt concentrations $0.1,0.2$ and $\geq 0.4 \%$. The recognition threshold was categorised as the salt concentrations $0 \cdot 1,0 \cdot 2-0 \cdot 4,0 \cdot 6-1 \cdot 0$ and $1 \cdot 2-1.6 \%$, and not recognising of $1.6 \%$ salt taste. The potential confounding factors included continuous BMI $\left(\mathrm{kg} / \mathrm{m}^{2}\right)$, smoking status (e.g. former or current) and grams of ethanol intake per d. For sensibility analyses of SBP and DBP according to detection and recognition thresholds, we excluded meidication users for hypertension. All analyses were performed using the SAS statistical package version 9.4 (SAS Institute Inc.). All probability values for statistical tests were two-tailed, and values of $P<0.05$ were regarded as indicative of statistical significance.

\section{Results}

Table 1 shows sex- and age-specific characteristics of the subjects in Akita (rural) and Osaka (urban) communities. Mean SBP was higher in Akita than in Osaka for women aged 60-74 years, but such a difference was not observed for men and women aged 30-59 years. Mean DBP did not differ between Akita and Osaka for both men and women of both age groups. The proportion of medication use for hypertension was higher in Akita than in Osaka for both men and women aged 60-74 years. Means of BMI were higher in Akita than in Osaka for women of both age groups. The proportion of overweight $\left(\mathrm{BMI} \geq 25.0 \mathrm{~kg} / \mathrm{m}^{2}\right.$ ) was higher in Akita than Osaka for women aged 60-74 years, but the opposite trend was observed for women aged 30-59 years. Such differences were not observed for men. The proportion of diabetes mellitus was higher in Akita than in Osaka for men aged 30-59 years, and the proportion of current smokers did not differ between Akita and Osaka for both men and women of both age groups. The proportion of current drinkers was higher in Akita than in Osaka for men aged 60-74 years, while the opposite trend was observed for women of both age groups.

Mean of the salt intake score was higher in Akita than in Osaka for women of both age groups but did not differ between them for men. For men and women of both age groups, the proportion of drinking salty soup (e.g. miso-soup) $\geq 2$ times/d was higher in Akita than in Osaka, while the proportion of adding soya or Western sauce before checking taste was higher in Osaka than in Akita. The proportion of eating salt-preserved food $\geq 3$ times/week was higher in Akita than in Osaka for men of both age groups and for women of 60-74 years, and the proportion of eating salt-preserved pickles $\geq 2$ times/d was higher in Akita than in Osaka for women of both age groups. The proportion of drinking up noodle soup was higher in Osaka than in Akita for men of both age groups and for women of 60-74 years, and the proportion of eating out $\geq 3$ times/ week was higher in Osaka than in Akita for men and women of $60-74$ years.

The distributions of detection and recognition thresholds are shown in Fig. 1. The proportion of detection for $0 \cdot 1 \%$ salt was similar between Akita and Osaka for both men and women: 61 and $62 \%$, respectively, for men and both $79 \%$ for women. The proportion of recognition for $0 \cdot 1 \%$ salt was $20 \%$ in Akita and $15 \%$ in Osaka for men ( $P$ for difference $=0.09$ ) and $32 \%$ and $24 \%$, respectively, for women ( $P$ for difference $=0 \cdot 01$ ). The proportion of no recognition for $1.6 \%$ salt taste was similar between Akita and Osaka: 34 and $30 \%$, respectively, for men, but lower in Akita (16\%) than in Osaka (21\%) for women ( $P$ for difference $=0 \cdot 01)$. 
Table 1. Sex- and age-specific characteristics of study subjects in Akita and Osaka (Mean values and standard deviations; numbers and percentages)

\begin{tabular}{|c|c|c|c|c|c|c|c|c|c|c|c|c|c|c|c|c|c|c|c|c|}
\hline & \multicolumn{10}{|c|}{ Men } & \multicolumn{10}{|c|}{ Women } \\
\hline & \multicolumn{5}{|c|}{$30-59$ years } & \multicolumn{5}{|c|}{$60-74$ years } & \multicolumn{5}{|c|}{$30-59$ years } & \multicolumn{5}{|c|}{$60-74$ years } \\
\hline & \multicolumn{2}{|c|}{ Akita (rural) } & \multicolumn{2}{|c|}{$\begin{array}{c}\text { Osaka } \\
\text { (urban) }\end{array}$} & \multirow{2}{*}{$\begin{array}{c}P \text { for } \\
\text { difference }\end{array}$} & \multicolumn{2}{|c|}{ Akita (rural) } & \multicolumn{2}{|c|}{$\begin{array}{l}\text { Osaka } \\
\text { (urban) }\end{array}$} & \multirow{2}{*}{$\begin{array}{c}P \text { for } \\
\text { difference }\end{array}$} & \multicolumn{2}{|c|}{ Akita (rural) } & \multicolumn{2}{|c|}{$\begin{array}{c}\text { Osaka } \\
\text { (urban) }\end{array}$} & \multirow{2}{*}{$\begin{array}{c}P \text { for } \\
\text { difference }\end{array}$} & \multicolumn{2}{|c|}{ Akita (rural) } & \multicolumn{2}{|c|}{$\begin{array}{l}\text { Osaka } \\
\text { (urban) }\end{array}$} & \multirow{2}{*}{$\begin{array}{c}P \text { for } \\
\text { difference }\end{array}$} \\
\hline & $\%$ & $n$ & $\%$ & $n$ & & $\%$ & $n$ & $\%$ & $n$ & & $\%$ & $n$ & $\%$ & $n$ & & $\%$ & $n$ & $\%$ & $n$ & \\
\hline No. of subjects & & 148 & & 135 & & & 279 & & 260 & & & 245 & & 398 & & & 352 & & 406 & \\
\hline \multicolumn{21}{|l|}{ Age (years) } \\
\hline Mean & & 46.4 & & 47.9 & 0.11 & & $66 \cdot 9$ & & 68.9 & $<0.001$ & & $46 \cdot 0$ & & 46.9 & 0.20 & & 66.9 & & 67.8 & 0.003 \\
\hline SD & & $8 \cdot 3$ & & 6.9 & & & $4 \cdot 1$ & & 3.9 & & & $8 \cdot 8$ & & $7 \cdot 4$ & & & $4 \cdot 0$ & & $4 \cdot 1$ & \\
\hline \multicolumn{21}{|l|}{ Systolic blood pressure $(\mathrm{mmHg})$} \\
\hline Mean & & $126 \cdot 2$ & & $126 \cdot 1$ & 0.95 & & $137 \cdot 0$ & & 135.6 & 0.34 & & $118 \cdot 8$ & & $116 \cdot 3$ & 0.08 & & $134 \cdot 3$ & & $130 \cdot 6$ & 0.005 \\
\hline SD & & 16.9 & & 16.4 & & & 17.9 & & $16 \cdot 1$ & & & 16.9 & & $17 \cdot 2$ & & & $18 \cdot 3$ & & $17 \cdot 3$ & \\
\hline \multicolumn{21}{|l|}{ Diastolic blood pressure $(\mathrm{mmHg})$} \\
\hline Mean & & 84.4 & & 84.5 & 0.92 & & $83 \cdot 1$ & & $82 \cdot 4$ & 0.42 & & $75 \cdot 7$ & & 75.9 & 0.79 & & 78.6 & & 78.9 & 0.70 \\
\hline SD & & $12 \cdot 0$ & & $13 \cdot 1$ & & & $10 \cdot 6$ & & $10 \cdot 6$ & & & $10 \cdot 5$ & & 11.4 & & & 9.6 & & $10 \cdot 1$ & \\
\hline Medication use for hypertension & $10 \cdot 6$ & & $6 \cdot 0$ & & 0.08 & $25 \cdot 2$ & & $18 \cdot 9$ & & 0.03 & 1.9 & & 4.0 & & 0.39 & 18.5 & & 16.9 & & 0.02 \\
\hline Hypertension & $26 \cdot 2$ & & 21.9 & & 0.49 & $36 \cdot 6$ & & 31.4 & & 0.16 & $7 \cdot 2$ & & $12 \cdot 3$ & & 0.74 & $28 \cdot 0$ & & 26.9 & & 0.01 \\
\hline \multicolumn{21}{|l|}{$\mathrm{BMI}\left(\mathrm{kg} / \mathrm{m}^{2}\right)$} \\
\hline Mean & & $24 \cdot 3$ & & $24 \cdot 2$ & 0.81 & & $24 \cdot 2$ & & 24.0 & 0.45 & & 22.5 & & 21.8 & 0.01 & & 23.7 & & 22.4 & $<0.001$ \\
\hline SD & & 3.7 & & 3.7 & & & 3.3 & & 3.1 & & & 3.9 & & 3.4 & & & 3.7 & & 3.1 & \\
\hline Overweight & $19 \cdot 8$ & & $18 \cdot 0$ & & 0.99 & 19.9 & & $17 \cdot 1$ & & 0.48 & $9 \cdot 0$ & & 9.2 & & 0.005 & $15 \cdot 3$ & & 9.8 & & $<0.001$ \\
\hline Diabetes mellitus & 7.8 & & 1.8 & & 0.001 & $10 \cdot 4$ & & $12 \cdot 1$ & & 0.17 & 1.7 & & 1.7 & & 0.24 & $7 \cdot 1$ & & 9.6 & & 0.33 \\
\hline Current smoker & $21 \cdot 2$ & & $19 \cdot 1$ & & 0.93 & $12 \cdot 6$ & & 11.0 & & 0.65 & $5 \cdot 1$ & & 6.4 & & 0.22 & 1.3 & & 1.6 & & 0.93 \\
\hline Current drinker & 36.8 & & 33.9 & & 0.88 & $40 \cdot 1$ & & 32.5 & & 0.01 & $10 \cdot 4$ & & $22 \cdot 6$ & & 0.02 & $6 \cdot 1$ & & $12 \cdot 9$ & & $<0.001$ \\
\hline Salt intake score (number) & & & & & & & & & & & & & & & & & & & & \\
\hline Mean & & $2 \cdot 6$ & & $2 \cdot 6$ & 0.93 & & $2 \cdot 0$ & & $2 \cdot 1$ & 0.36 & & 1.6 & & 1.3 & 0.002 & & 1.6 & & 1.2 & $<0.001$ \\
\hline SD & & 1.6 & & 1.5 & & & 1.4 & & 1.5 & & & 1.1 & & 1.2 & & & 1.3 & & 1.2 & \\
\hline Seasoning all food salty (yes) & $22 \cdot 3$ & & $19 \cdot 8$ & & 0.85 & $17 \cdot 6$ & & $16 \cdot 0$ & & 0.81 & $14 \cdot 3$ & & $17 \cdot 3$ & & 0.01 & $16 \cdot 6$ & & 11.5 & & $<0.001$ \\
\hline Salty soup (miso-soup etc.) $\geq 2$ times $/ \mathrm{d}$ & $16 \cdot 3$ & & $7 \cdot 1$ & & 0.001 & $17 \cdot 6$ & & $5 \cdot 0$ & & $<0.001$ & 8.2 & & 4.5 & & $<0.001$ & 11.6 & & $3 \cdot 2$ & & $<0.001$ \\
\hline Drinking up noodle soup (yes) & $18 \cdot 0$ & & 23.3 & & 0.01 & $12 \cdot 8$ & & $17 \cdot 8$ & & $<0.001$ & 3.4 & & 7.6 & & 0.19 & 1.9 & & 5.5 & & $<0.001$ \\
\hline Salt-preserved foods $\geq 3$ times/week & $11 \cdot 0$ & & $4 \cdot 2$ & & 0.005 & 13.4 & & $6 \cdot 3$ & & $<0.001$ & $5 \cdot 0$ & & 3.1 & & $<0.001$ & 8.6 & & 7.9 & & 0.17 \\
\hline $\begin{array}{l}\text { Putting on soya or Western sauce before } \\
\text { checking taste }\end{array}$ & $9 \cdot 2$ & & $21 \cdot 2$ & & $<0.001$ & $8 \cdot 7$ & & $14 \cdot 3$ & & $<0.001$ & 0.5 & & 4.8 & & $<0.001$ & 0.8 & & 4.0 & & $<0.001$ \\
\hline Salt-preserved pickles $\geq 2$ times $/ \mathrm{d}$ & $5 \cdot 7$ & & $5 \cdot 3$ & & 0.94 & $14 \cdot 1$ & & 11.3 & & 0.31 & $4 \cdot 0$ & & 3.9 & & 0.05 & $16 \cdot 0$ & & 9.8 & & $<0.001$ \\
\hline Eating out $\geq 0$ ce/week & $22 \cdot 3$ & & $16 \cdot 6$ & & 0.18 & $7 \cdot 1$ & & $15 \cdot 8$ & & $<0.001$ & 7.6 & & $14 \cdot 2$ & & 0.39 & 4.2 & & 9.4 & & $<0.001$ \\
\hline Delicatessen $\geq$ once/week & $29 \cdot 3$ & & $25 \cdot 4$ & & 0.64 & $10 \cdot 8$ & & 14.3 & & 0.02 & $25 \cdot 8$ & & 18.2 & & 0.13 & $13 \cdot 2$ & & $12 \cdot 8$ & & 0.16 \\
\hline
\end{tabular}



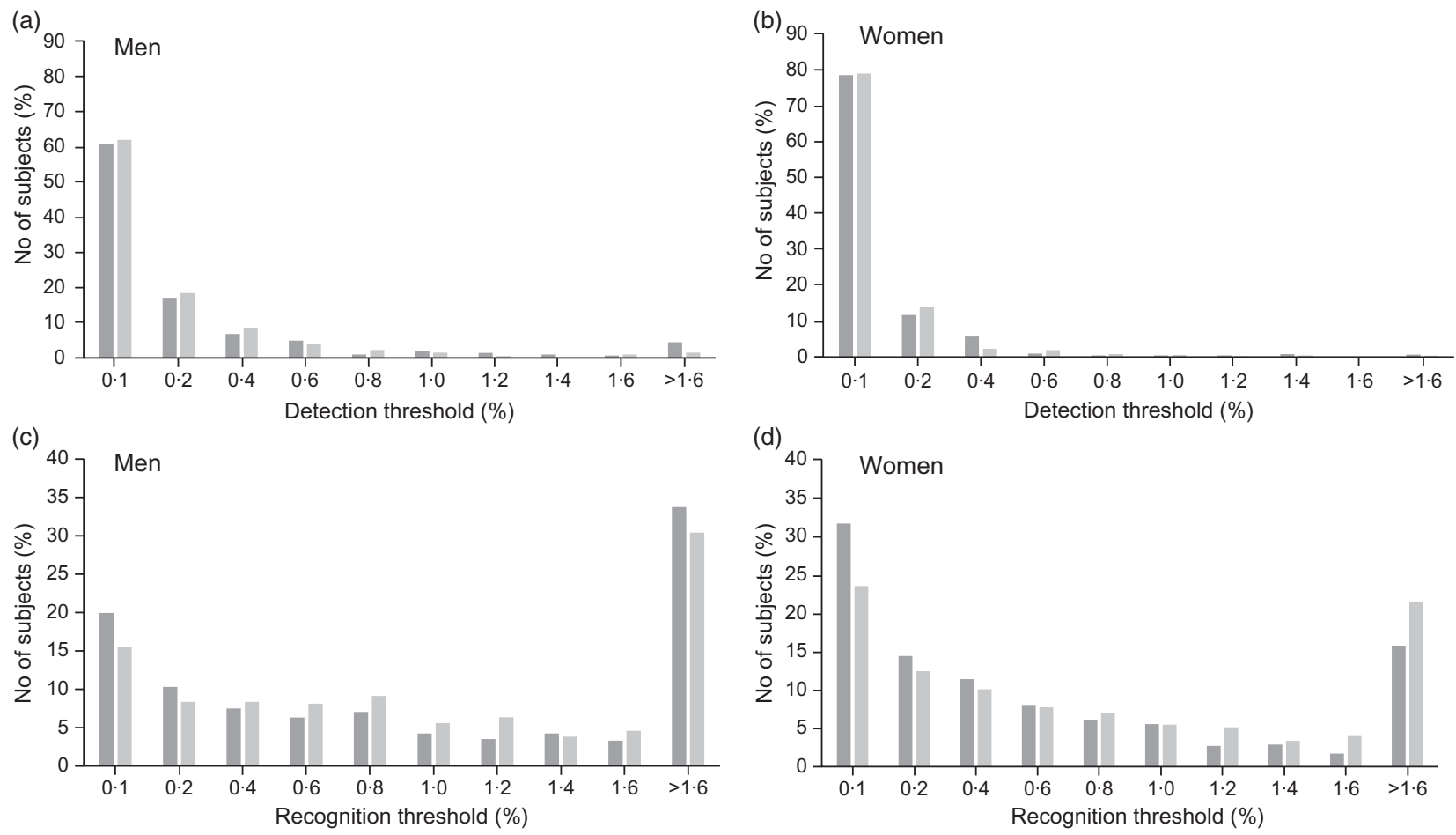

Fig. 1. Distributions of detection $(a, b)$ and recognition $(c, d)$ thresholds to salt taste in Akita $(\square)$ and Osaka ( $\square$ ). $>1 \cdot 6$ : not recognising of $1.6 \%$ salt taste.

When we further examined the detection and recognition thresholds by age group (Table 2), the detection threshold distribution was higher in Akita than in Osaka for women aged 60-74 years ( $P$ for difference $=0 \cdot 03$ ) but did not differ between them for men of both age groups and for women of 30-59 years. The recognition threshold distribution was lower in Akita than in Osaka for women of both age groups ( $P$ for difference $<0.002$ in $30-59$ years and $<0.05$ in 60-74 years) but did not differ between them for men.

Sex- and age-specific means and standard errors of salt intake scores according to detection and recognition thresholds in Akita and Osaka are shown in Table 3. Mean salt intake scores tended to be higher with higher detection and recognition thresholds in Akita men aged 30-59 years ( $P$ for trend $=0 \cdot 13$ and $=0 \cdot 05$, respectively). Among Akita women aged 60-74 years, mean salt intake scores tended to be higher with higher detection threshold ( $P$ for trend $=0.06$ ); however, mean salt intake scores tended to be lower with higher recognition threshold ( $P$ for trend $=0.07$ ). Such trends were not observed for other sex- and age groups in Akita and Osaka. Similar results were observed when we excluded the medication users for sex and age hypertension (online Supplementary Table S1).

Tables 4 and 5 indicate age-specific means and standard errors of SBP and DBP according to detection and recognition thresholds for men and women, respectively, in Akita and Osaka. Among Akita men aged 30-59 years, mean SBP and DBP tended to be higher with higher detection threshold ( $P_{\text {for trend }}=0.08$ for SBP and $=0.09$ for DBP), and mean DBP was higher with higher recognition threshold $\left(P_{\text {for trend }}=0.03\right)$. Among Akita women aged 30-59 years, mean SBP was higher with higher recognition threshold $\left(P_{\text {for trend }}=0.02\right)$. Among
Akita men aged 60-74 years, mean SBP tended to be higher and mean DBP was higher with higher detection threshold ( $P_{\text {for trend }}=0.09$ and $=0.002$, respectively), while mean DBP was lower with higher recognition threshold $\left(P_{\text {for trend }}=0 \cdot 04\right)$. Among Akita women aged 60-74 years, mean DBP was lower with higher detection threshold $\left(P_{\text {for trend }}=0.03\right)$. Similar results were observed when we excluded the medication users for hypertension (online Supplementary Tables S2 and S3).

\section{Discussion}

In this population-based cross-sectional study of Akita and Osaka communities, our findings indicated that women were more likely to recognise salt taste than men in both communities. A previous report from the SONIC study on Japanese aged 69-71 years (477 men and 519 women) and 79-81 years (449 men and 500 women) showed that the recognition for salt taste was better in women than in men of both age groups ${ }^{(22)}$. In that study, the proportion of non-recognition for $>0.5 \%$ salt was $6.7 \%$ in subjects aged $69-71$ years and $13.2 \%$ in those aged $79-81$ years.

In the present study, detection and recognition thresholds tended to be associated with higher salt intake scores for Akita men aged 30-59years, in which SBP was positively associated with detection and recognition thresholds after adjustment for potential confounding factors such as BMI, smoking status and usual ethanol intake. Similarly, DBP tended to be associated with detection and recognition thresholds. A previous cross-sectional study of eighteen hypertensives and twenty-two normotensives aged 19-70 years indicated that higher salt 
Table 2. Sex- and age-specific proportions for distributions of detection and recognition thresholds of salt in Akita and Osaka (Numbers and percentages)

\begin{tabular}{|c|c|c|c|c|c|c|c|c|c|c|c|c|c|c|c|c|c|c|c|c|}
\hline & \multicolumn{10}{|c|}{ Men } & \multicolumn{10}{|c|}{ Women } \\
\hline & \multicolumn{5}{|c|}{$30-59$ years } & \multicolumn{5}{|c|}{$60-74$ years } & \multicolumn{5}{|c|}{ 30-59 years } & \multicolumn{5}{|c|}{$60-74$ years } \\
\hline & \multicolumn{2}{|c|}{$\begin{array}{l}\text { Akita } \\
\text { (rural) }\end{array}$} & \multicolumn{2}{|c|}{$\begin{array}{l}\text { Osaka } \\
\text { (urban) }\end{array}$} & \multirow[b]{2}{*}{$P$ for difference } & \multicolumn{2}{|c|}{$\begin{array}{l}\text { Akita } \\
\text { (rural) }\end{array}$} & \multicolumn{2}{|c|}{$\begin{array}{l}\text { Osaka } \\
\text { (urban) }\end{array}$} & \multirow[b]{2}{*}{$P$ for difference } & \multicolumn{2}{|c|}{$\begin{array}{l}\text { Akita } \\
\text { (rural) }\end{array}$} & \multicolumn{2}{|c|}{$\begin{array}{l}\text { Osaka } \\
\text { (urban) }\end{array}$} & \multirow[b]{2}{*}{$P$ for difference } & \multicolumn{2}{|c|}{$\begin{array}{l}\text { Akita } \\
\text { (rural) }\end{array}$} & \multicolumn{2}{|c|}{$\begin{array}{l}\text { Osaka } \\
\text { (urban) }\end{array}$} & \multirow[b]{2}{*}{$P$ for difference } \\
\hline & $\%$ & $n$ & $\%$ & $n$ & & $\%$ & $n$ & $\%$ & $n$ & & $\%$ & $n$ & $\%$ & $n$ & & $\%$ & $n$ & $\%$ & $n$ & \\
\hline No. of subjects & & 148 & & 279 & & & 135 & & 260 & & & 245 & & 352 & & & 398 & & 406 & \\
\hline \multicolumn{21}{|l|}{ Detection } \\
\hline Median of detection threshold & 0.1 & & 0.1 & & & 0.1 & & 0.1 & & & 0.1 & & 0.1 & & & 0.1 & & 0.1 & & \\
\hline $0.1 \%$ & 67.6 & & 63.0 & & 0.29 & 57.4 & & 61.5 & & 0.20 & 84.5 & & 80.9 & & 0.55 & $74 \cdot 4$ & & 77.1 & & 0.03 \\
\hline $0.2 \%$ & 14.9 & & $19 \cdot 3$ & & & $18 \cdot 3$ & & $18 \cdot 1$ & & & 9.0 & & 13.1 & & & 13.6 & & $14 \cdot 8$ & & \\
\hline $0.4 \%$ & $6 \cdot 1$ & & 7.4 & & & $7 \cdot 2$ & & 9.2 & & & 4.5 & & 2.8 & & & 6.5 & & 2.0 & & \\
\hline $0.6 \%$ & 5.4 & & 4.4 & & & 4.7 & & 3.9 & & & 1.2 & & 1.8 & & & 0.9 & & $2 \cdot 2$ & & \\
\hline $0.8 \%$ & 0.0 & & 3.0 & & & 1.4 & & 1.9 & & & 0.0 & & 0.3 & & & 0.9 & & 1.5 & & \\
\hline $1.0 \%$ & $2 \cdot 0$ & & 0.7 & & & 1.8 & & 1.9 & & & 0.4 & & 0.5 & & & 0.6 & & 0.7 & & \\
\hline $1.2 \%$ & 0.7 & & 0.7 & & & 1.8 & & 0.4 & & & 0.0 & & 0.0 & & & 0.9 & & 0.5 & & \\
\hline $1.4 \%$ & 0.7 & & 0.0 & & & 1.1 & & 0.0 & & & 0.0 & & 0.3 & & & 1.4 & & 0.7 & & \\
\hline $1.6 \%$ & 0.0 & & 0.7 & & & 1.1 & & $1 \cdot 2$ & & & 0.0 & & 0.3 & & & 0.0 & & 0.0 & & \\
\hline$>1.6 \%{ }^{*}$ & 2.7 & & 0.7 & & & $5 \cdot 4$ & & 1.9 & & & 0.4 & & 0.3 & & & 0.9 & & 0.5 & & \\
\hline \multicolumn{21}{|l|}{ Recognition } \\
\hline Median of recognition threshold & 0.4 & & 1.2 & & & 0.8 & & 1.0 & & & 0.2 & & 0.4 & & & 0.4 & & 0.6 & & \\
\hline $0.1 \%$ & 30.4 & & 20.0 & & 0.43 & 14.3 & & $13 \cdot 1$ & & 0.56 & 38.4 & & $27 \cdot 1$ & & 0.002 & $27 \cdot 0$ & & $20 \cdot 0$ & & 0.05 \\
\hline $0.2 \%$ & $15 \cdot 5$ & & 11.9 & & & 7.5 & & 6.5 & & & $15 \cdot 9$ & & $12 \cdot 3$ & & & 13.4 & & 12.6 & & \\
\hline $0.4 \%$ & $6 \cdot 1$ & & 4.4 & & & $8 \cdot 2$ & & 10.4 & & & 11.4 & & 11.3 & & & 11.4 & & 8.9 & & \\
\hline $0.6 \%$ & 6.8 & & 10.4 & & & $6 \cdot 1$ & & 6.9 & & & 9.4 & & 6.5 & & & $7 \cdot 1$ & & 8.9 & & \\
\hline $0.8 \%$ & $7 \cdot 4$ & & 8.9 & & & 6.8 & & 9.2 & & & 3.7 & & 6.5 & & & 7.7 & & 7.4 & & \\
\hline $1.0 \%$ & 4.1 & & $8 \cdot 2$ & & & 4.3 & & 4.2 & & & 4.5 & & 6.0 & & & 6.3 & & 4.9 & & \\
\hline $1.2 \%$ & 4.1 & & $5 \cdot 2$ & & & $3 \cdot 2$ & & 6.9 & & & 3.3 & & 3.8 & & & $2 \cdot 3$ & & 6.4 & & \\
\hline $1.4 \%$ & 2.7 & & 3.0 & & & 5.0 & & 4.2 & & & 2.5 & & 2.8 & & & 3.1 & & 3.9 & & \\
\hline $1.6 \%$ & 2.0 & & 4.4 & & & 3.9 & & 4.6 & & & 1.2 & & 4.5 & & & 2.0 & & 3.5 & & \\
\hline$>1.6 \%{ }^{*}$ & 21.0 & & 23.7 & & & 40.5 & & 33.9 & & & 9.8 & & 19.1 & & & 19.9 & & 23.7 & & \\
\hline
\end{tabular}

* $>1.6 \%$ : not recognising of $1.6 \%$ salt taste. 
Table 3. Salt intake scores according to detection and recognition thresholds in Akita and Osaka

(Sex- and age-specific mean values with their standard errors; numbers)

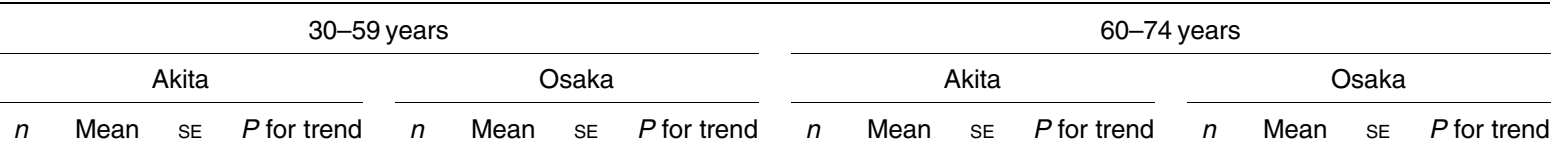

Men

Detection

$\begin{array}{lllllllllllllllll}0.1 \% & 100 & 2.5 & 0.2 & 0.13 & 85 & 2.5 & 0.2 & 0.26 & 160 & 2.0 & 0.1 & 0.99 & 160 & 2.0 & 0.1 & 0.38\end{array}$

$\begin{array}{llll}0.2 \% & 22 & 2.5 & 0.3\end{array}$

$\geq 0.4 \% \quad 26 \quad 3.0 \quad 0.3$

Recognition

$0.1 \% \quad 45 \quad 2 \cdot 2 \quad 0$

$0.2-0.4 \% \quad 32 \quad 2.5 \quad 0.3$

$0.6-0.8 \% \quad 21 \quad 3.0 \quad 0.3$

$1.0-1.6 \% \quad 19 \quad 2.1 \quad 0.4$

$\begin{array}{llll}>1.6 \% \%^{*} & 31 & 3.1 & 0.3\end{array}$

Women

Detection

\begin{tabular}{|c|c|c|c|c|c|c|c|c|c|c|c|c|c|c|c|c|}
\hline $0.1 \%$ & 207 & 1.6 & 0.1 & 0.99 & 322 & $1 \cdot 3$ & 0.1 & 0.49 & 262 & 1.5 & 0.1 & 0.06 & 313 & $1 \cdot 2$ & 0.1 & 0.39 \\
\hline $0.2 \%$ & 22 & $2 \cdot 1$ & 0.2 & & 52 & 1.2 & 0.2 & & 48 & 1.3 & 0.2 & & 60 & $1 \cdot 3$ & 0.2 & \\
\hline $\begin{array}{l}\geq 0.4 \% \\
\text { Recognition }\end{array}$ & 16 & $1 \cdot 3$ & 0.3 & & 24 & $1 \cdot 3$ & 0.2 & & 42 & $2 \cdot 1$ & 0.2 & & 33 & $1 \cdot 3$ & 0.2 & \\
\hline $0.1 \%$ & 94 & 1.7 & 0.1 & 0.50 & 108 & 1.3 & 0.1 & 0.20 & 95 & 1.6 & 0.1 & 0.07 & 81 & 1.2 & 0.1 & 0.99 \\
\hline $0.2-0.4 \%$ & 67 & 1.6 & 0.1 & & 94 & 1.3 & 0.1 & & 87 & 1.9 & 0.1 & & 87 & $1 \cdot 2$ & 0.1 & \\
\hline $0.6-0.8 \%$ & 32 & 1.3 & 0.2 & & 52 & 1.2 & 0.2 & & 52 & 1.4 & 0.2 & & 66 & $1 \cdot 2$ & 0.1 & \\
\hline $1.0-1.6 \%$ & 28 & 1.5 & 0.2 & & 68 & 1.4 & 0.1 & & 48 & 1.5 & 0.2 & & 76 & 1.3 & 0.1 & \\
\hline$>1.6 \%$ * & 24 & 1.8 & 0.2 & & 76 & 1.5 & 0.1 & & 70 & 1.4 & 0.2 & & 96 & $1 \cdot 1$ & 0.1 & \\
\hline
\end{tabular}

${ }^{*}>1.6 \%$ : not recognising of $1.6 \%$ salt taste.

Table 4. Systolic and diastolic blood pressures according to detection and recognition thresholds for men in Akita and Osaka*

(Age-specific mean values with their standard errors)

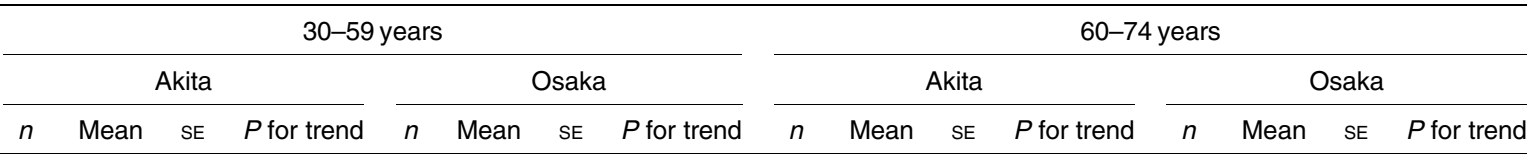

Systolic blood pressure

Detection

\begin{tabular}{|c|c|c|c|c|c|c|c|c|c|c|c|c|c|c|c|}
\hline $0.1 \%$ & 100 & $124 \cdot 8$ & $1 \cdot 7$ & 0.08 & 85 & 125.5 & 1.5 & 0.81 & 160 & $135 \cdot 6$ & 1.4 & 0.09 & 160 & 135.4 & $1 \cdot 3$ \\
\hline $0.2 \%$ & 22 & $126 \cdot 3$ & 3.5 & & 26 & $130 \cdot 8$ & $2 \cdot 8$ & & 51 & $137 \cdot 6$ & $2 \cdot 5$ & & 47 & $131 \cdot 5$ & $2 \cdot 3$ \\
\hline $\begin{array}{l}\geq 0.4 \% \\
\text { Recognition }\end{array}$ & 26 & 131.6 & $3 \cdot 3$ & & 24 & $122 \cdot 8$ & 2.9 & & 68 & 139.8 & $2 \cdot 1$ & & 53 & 139.8 & $2 \cdot 2$ \\
\hline $0.1 \%$ & 45 & 121.9 & $2 \cdot 4$ & 0.03 & 27 & $127 \cdot 8$ & $2 \cdot 8$ & 0.26 & 40 & $139 \cdot 2$ & $2 \cdot 8$ & 0.77 & 34 & $138 \cdot 0$ & \\
\hline $0.2 \%-0.4 \%$ & 32 & $127 \cdot 9$ & 2.9 & & 22 & $127 \cdot 8$ & $3 \cdot 1$ & & 44 & 138.8 & 2.7 & & 44 & 133.4 & 2.4 \\
\hline $0.6 \%-0.8 \%$ & 21 & $125 \cdot 6$ & 3.6 & & 26 & $127 \cdot 4$ & $2 \cdot 9$ & & 36 & $131 \cdot 8$ & 3.0 & & 42 & $131 \cdot 2$ & \\
\hline $1.0 \%-1.6 \%$ & 19 & 121.4 & $3 \cdot 7$ & & 28 & $122 \cdot 4$ & $2 \cdot 7$ & & 46 & $135 \cdot 1$ & $2 \cdot 6$ & & 52 & $138 \cdot 8$ & \\
\hline$>1.6 \% \dagger$ & 31 & $133 \cdot 9$ & 3.0 & & 32 & 125.5 & $2 \cdot 6$ & & 113 & $137 \cdot 9$ & $1 \cdot 7$ & & 88 & 135.9 & \\
\hline
\end{tabular}

Diastolic blood pressure

Detection

\begin{tabular}{|c|c|c|c|c|c|c|c|c|c|c|c|c|c|c|c|c|}
\hline $0.1 \%$ & 100 & 83.6 & $1 \cdot 2$ & 0.09 & 85 & $84 \cdot 3$ & $1 \cdot 2$ & 0.56 & 160 & 81.6 & 0.8 & 0.002 & 160 & $82 \cdot 0$ & 0.8 & 0.29 \\
\hline $0.2 \%$ & 22 & $82 \cdot 7$ & 2.5 & & 26 & $88 \cdot 1$ & $2 \cdot 2$ & & 51 & 83.3 & 1.5 & & 47 & $82 \cdot 1$ & 1.5 & \\
\hline $\begin{array}{l}\geq 0.4 \% \\
\text { Recognition }\end{array}$ & 26 & 88.9 & $2 \cdot 3$ & & 24 & $81 \cdot 3$ & $2 \cdot 3$ & & 68 & 86.5 & $1 \cdot 3$ & & 53 & 83.9 & 1.4 & \\
\hline $0.1 \%$ & 45 & $82 \cdot 0$ & 1.8 & 0.15 & 27 & $86 \cdot 6$ & $2 \cdot 2$ & 0.22 & 40 & 84.5 & 1.7 & 0.04 & 34 & 82.4 & 1.8 & 0.67 \\
\hline $0.2 \%-0.4 \%$ & 32 & 86.0 & $2 \cdot 1$ & & 22 & 85.0 & 2.5 & & 44 & $86 \cdot 7$ & 1.6 & & 44 & 81.5 & 1.6 & \\
\hline $0.6 \%-0.8 \%$ & 21 & $83 \cdot 2$ & $2 \cdot 6$ & & 26 & $86 \cdot 5$ & $2 \cdot 3$ & & 36 & 81.9 & $1 \cdot 8$ & & 42 & $81 \cdot 0$ & 1.6 & \\
\hline $1.0 \%-1.6 \%$ & 19 & 84.2 & 2.7 & & 28 & 80.5 & $2 \cdot 2$ & & 46 & 81.9 & 1.6 & & 52 & $84 \cdot 7$ & 1.5 & \\
\hline$>1.6 \% \dagger$ & 31 & $87 \cdot 1$ & $2 \cdot 2$ & & 32 & $84 \cdot 4$ & $2 \cdot 0$ & & 113 & $82 \cdot 1$ & 1.0 & & 88 & $82 \cdot 1$ & $1 \cdot 1$ & \\
\hline
\end{tabular}

* Adjusted for BMI, smoking status and ethanol intake.

$\dagger>1.6 \%$ : not recognising of $1.6 \%$ salt taste.

recognition threshold (ranging 0.03 to $2.6 \%$ ) was associated with higher 24-h urinary $\mathrm{Na}$ excretion ${ }^{(8)}$. A cross-cultural study of sixty-four Myanmarese men and women aged 53.3 (SD 9.4) years and sixty-seven Korean men and women aged 56.4 (SD
10.7) years in clinical settings showed that Myanmarese adults had higher salt detection and recognition thresholds, salt preference, salt usage behaviour scores and higher mean SBP and DBP than Koreans adults ${ }^{(15)}$. That study also reported that detection 
Table 5. Systolic and diastolic blood pressures according to detection and recognition thresholds for women in Akita and Osaka* (Age-specific mean values with their standard errors)

\begin{tabular}{|c|c|c|c|c|c|c|c|c|c|c|c|c|c|c|c|c|}
\hline & \multicolumn{8}{|c|}{$30-59$ years } & \multicolumn{8}{|c|}{$60-74$ years } \\
\hline & \multicolumn{4}{|c|}{ Akita } & \multicolumn{4}{|c|}{ Osaka } & \multicolumn{4}{|c|}{ Akita } & \multicolumn{4}{|c|}{ Osaka } \\
\hline & $n$ & Mean & SE & $P$ for trend & $n$ & Mean & SE & $P$ for trend & $n$ & Mean & SE & $P$ for trend & $n$ & Mean & $\mathrm{SE}$ & $P$ for trend \\
\hline \multicolumn{17}{|c|}{ Systolic blood pressure } \\
\hline \multicolumn{17}{|l|}{ Detection } \\
\hline $0.1 \%$ & 207 & $118 \cdot 3$ & $1 \cdot 1$ & 0.16 & 322 & $116 \cdot 1$ & 0.9 & 0.85 & 262 & $134 \cdot 6$ & $1 \cdot 1$ & 0.14 & 313 & $130 \cdot 2$ & 1.0 & 0.28 \\
\hline $0.2 \%$ & 22 & 118.3 & $3 \cdot 4$ & & 52 & $118 \cdot 1$ & $2 \cdot 3$ & & 48 & 137.6 & $2 \cdot 6$ & & 60 & $130 \cdot 8$ & $2 \cdot 2$ & \\
\hline$\geq 0.4 \%$ & 16 & $125 \cdot 0$ & 3.9 & & 24 & $115 \cdot 0$ & 3.4 & & 42 & $128 \cdot 3$ & $2 \cdot 8$ & & 33 & $133 \cdot 8$ & 3.0 & \\
\hline \multicolumn{17}{|l|}{ Recognition } \\
\hline $0.1 \%$ & 94 & $116 \cdot 4$ & 1.6 & 0.02 & 108 & $113 \cdot 6$ & 1.6 & 0.08 & 95 & $136 \cdot 7$ & 1.8 & 0.35 & 81 & $131 \cdot 8$ & 1.9 & 0.08 \\
\hline $0.2-0.4 \%$ & 67 & 118.4 & 1.9 & & 94 & $116 \cdot 8$ & $1 \cdot 7$ & & 87 & $133 \cdot 1$ & 1.9 & & 87 & $132 \cdot 2$ & 1.8 & \\
\hline $0.6-0 / 8 \%$ & 32 & 120.5 & $2 \cdot 8$ & & 52 & 114.5 & $2 \cdot 2$ & & 52 & $133 \cdot 0$ & 2.5 & & 66 & $128 \cdot 7$ & $2 \cdot 1$ & \\
\hline $1.0-1.6 \%$ & 28 & $120 \cdot 4$ & $3 \cdot 0$ & & 68 & $121 \cdot 8$ & $2 \cdot 0$ & & 48 & $133 \cdot 7$ & $2 \cdot 6$ & & 76 & $130 \cdot 2$ & $2 \cdot 0$ & \\
\hline$>1.6 \% \dagger$ & 24 & 124.5 & $3 \cdot 2$ & & 76 & $115 \cdot 8$ & 1.9 & & 70 & 133.7 & $2 \cdot 2$ & & 96 & $129 \cdot 7$ & 1.7 & \\
\hline \multicolumn{17}{|c|}{ Diastolic blood pressure } \\
\hline \multicolumn{17}{|c|}{ Detection } \\
\hline $0.1 \%$ & 207 & $75 \cdot 8$ & 0.7 & 0.91 & 322 & $75 \cdot 7$ & 0.6 & 0.51 & 262 & $79 \cdot 2$ & 0.6 & 0.03 & 313 & 78.6 & 0.6 & 0.11 \\
\hline $0.2 \%$ & 22 & 73.9 & $2 \cdot 2$ & & 52 & $77 \cdot 2$ & 1.5 & & 48 & $77 \cdot 6$ & 1.4 & & 60 & $78 \cdot 3$ & 1.3 & \\
\hline$\geq 0.4 \%$ & 16 & $77 \cdot 2$ & 2.5 & & 24 & $76 \cdot 1$ & $2 \cdot 2$ & & 42 & 75.9 & 1.5 & & 33 & $82 \cdot 4$ & 1.8 & \\
\hline \multicolumn{17}{|l|}{ Recognition } \\
\hline $0.1 \%$ & 94 & $76 \cdot 1$ & $1 \cdot 0$ & 0.96 & 108 & $74 \cdot 7$ & $1 \cdot 0$ & 0.61 & 95 & $80 \cdot 2$ & $1 \cdot 0$ & 0.10 & 81 & $79 \cdot 0$ & $1 \cdot 1$ & 0.65 \\
\hline $0.2-0.4 \%$ & 67 & 74.5 & $1 \cdot 2$ & & 94 & 76.5 & $1 \cdot 1$ & & 87 & 78.0 & 1.0 & & 87 & $77 \cdot 6$ & $1 \cdot 1$ & \\
\hline $0.6-0.8 \%$ & 32 & 77.9 & 1.8 & & 52 & 76.4 & 1.5 & & 52 & 78.0 & $1 \cdot 3$ & & 66 & 79.0 & 1.2 & \\
\hline $1.0-1.6 \%$ & 28 & $73 \cdot 1$ & 1.9 & & 68 & 77.9 & 1.3 & & 48 & 78.8 & 1.4 & & 76 & 80.5 & 1.2 & \\
\hline$>1.6 \% \dagger$ & 24 & 77.5 & $2 \cdot 1$ & & 76 & 74.8 & 1.3 & & 70 & $77 \cdot 3$ & $1 \cdot 2$ & & 96 & 78.4 & 1.0 & \\
\hline
\end{tabular}

${ }^{*}$ Adjusted for BMI, smoking status and ethanol intake.

$\dagger>1.6 \%$ : not recognising of $1.6 \%$ salt taste.

and recognition thresholds were positively associated with SBP levels, but confounding factors such as age, sex, BMI and hypertension were not considered. According to a study of 421 Brazilian adolescents aged 14-19 years, salt recognition threshold was positively associated with DBP levels after the adjustment for age, sex, BMI and physical activity ${ }^{(14)}$. A Japanese study of 344 men and 479 women aged $\geq 40$ years showed that women with high salt recognition threshold $(\geq 1.0 \%)$ compared with $<1.0 \%$ recognition were associated with a 2.47 times higher prevalence of hypertension after adjustment for age, BMI, casual blood glucose, total cholesterol, presence of artificial teeth, smoking and alcohol consumption ${ }^{(16)}$. In that study, such an association was not observed for men.

Our a priori hypotheses are that thresholds for salt recognition and detection are higher in Akita than Osaka and that higher thresholds are associated with higher salt intake and blood pressure levels in both communities. Such trends were expected to be observed similarly for both men and middle-aged women. Our findings agreed with our hypothesis, but the findings among other sex, age and area groups did not concur. Among Akita women aged 60-74 years, higher recognition threshold tended to be associated with lower salt intake scores, and higher detection and recognition thresholds were associated with lower blood pressure levels. These results may be due in part to an effect of long-term intervention programmes for the prevention of hypertension and stroke, which has been conducted in the Akita community since $1964^{(5,23)}$. Along with systematic screenings to detect hypertensives and education programmes for salt reduction, mean salt intake has declined substantially ${ }^{(4)}$. In the UK, the average salt intake of the national representable samples aged 19-64 years gradually decreased from $9.5 \mathrm{~g} / \mathrm{d}$ in 2003 to $8 \cdot 1 \mathrm{~g} / \mathrm{d}$ in 2011 due to a national programme of lowing Na concentrations in processed foods, especially bread ( $1.23 \mathrm{~g}$ salt $/ 100 \mathrm{~g}$ bread to $0.98 \mathrm{~g} / 100 \mathrm{~g})$. Mean levels of systolic and diastolic blood pressure levels decreased in parallel by 2.7 and $1.1 \mathrm{mmHg}$, respectively ${ }^{(24,25)}$. In our study populations, we have conducted education for salt reduction, instead of a programme for salt reduction in processed foods. In the elderly in Akita, salt intake behaviour may have been modified by our education programme ${ }^{(23)}$.

We assume that salt reduction education may contribute to reduce salt intake and to lower blood pressure in levels, regardless of salt perception. Salt intake in the Osaka community has been lower than in the Akita community; hence, the associations observed in middle-aged Akita men were unlikely to be detected.

A strength of the present study was including large samples in community-based settings, so that our study findings could be generalised to Japanese populations. Second, we defined the recognition thresholds using two consecutive concentrations to confirm them more reliably unlike previous studies ${ }^{(14-16)}$. However, several limitations should be mentioned. Due to the cross-sectional design, we could not confirm temporal relationships of salt detection and recognition with salt intake and blood pressure levels. A study of twenty-nine chronic kidney patients showed that the average salt recognition thresholds declined after 1 week of $\mathrm{Na}$ restriction ${ }^{(26)}$, but the causality was not confirmed because of no control setting.

In conclusion, we found that the higher thresholds of salt perception were positively associated with salt intake behaviours 
and higher blood pressure levels among rural men and middleaged women who may have higher salt intake than other sex, age and area groups. Our findings suggest that salt perception should be taken into account to modify salt intake for populations with high salt intake.

\section{Acknowledgements}

The authors acknowledge Dr Megumi Murakami for her contribution to the measurement of $\mathrm{Na}$ concentration by a polarised Zeeman atomic absorption spectrophotometer. The authors are grateful for the contributions of the public health nurses, nutritionists, nurses, medical technologists and other staff of the Osaka Medical Center for Health Science and Promotion.

This work had financial support in 2015 from SKYLARK Food Science Institute.

SKYLARK Food Science Institute had no role in the design, analysis or writing of this article.

The authors' responsibilities were as follows: A. K., A. K., H. I., R. C., M. U., K. Y., T. O., I. M., M. H.-T., M. K. and H. I. all contributed to the conception and design of the study. A. K. analysed the data. A. K., A. K. and H. I. drafted the manuscript. All authors contributed to manuscript preparation and revision for intellectual content.

The authors declare that there are no conflicts of interest.

\section{Supplementary material}

For supplementary material referred to in this article, please visit https://doi.org/10.1017/S0007114520002640

\section{References}

1. World Health Organization (2011) Global Status Report on Noncommunicable Diseases. Geneva: World Health Organization.

2. Ministry of Health, Labour and Welfare of Japan (2014) Kokumin Kennko-Eiyo no Gennjyo 2012 (The National Health and Nutrition Survey in Japan, 2012). Tokyo: Daiichi Shuppan.

3. Ikeda N, Saito E, Kondo N, et al. (2011) What has made the population of Japan healthy? Lancet 378, 1094-1105.

4. Kitamura A, Sato S, Kiyama M, et al. (2008) Trends in the incidence of coronary heart disease and stroke and their risk factors in Japan, 1964 to 2003: the Akita-Osaka study. J Am Coll Cardiol 52, 71-79.

5. Shimamoto T, Komachi Y, Inada H, et al. (1989) Trends for coronary heart disease and stroke and their risk factors in Japan. Circulation 79, 503-515.

6. Ministry of Health, Labour and Welfare of Japan (2019) Kokumin Kennko-Eiyo no Gennjyo 2017 (The National Health and Nutrition Survey in Japan, 2017). Tokyo: Daiichi Shuppan.

7. World Health Organization (2012) Guideline: Sodium Intake for Adults and Children. Geneva: World Health Organization.
8. Azinge EC, Sofola OA \& Silva BO (2011) Relationship between salt intake, salt-taste threshold and blood pressure in Nigerians. West Afr J Med 30, 373-376.

9. Piovesana PDM, Sampaio KDL \& Gallani MCBJ (2013) Association between taste sensitivity and self-reported and objective measures of salt intake among hypertensive and normotensive individuals. ISRN Nutr 2013, 301213.

10. Fallis N \& Lasagna LTL (1962) Gustatory thresholds in patients with hypertension. Nature 196, 74-75.

11. Henkin RI (1974) Salt taste in patients with essential hypertension and with hypertension due to primary hyperaldosteronism. J Chronic Dis 27, 235-244.

12. Amen FM \& Raza HFH (2015) Salty taste threshold in hypertensive patients taking certain types of anti-hypertensive medication compare to healthy individuals. JBR J Interdiscip 3, 4-6.

13. Mattes RD (1997) The taste for salt in humans. Am J Clin Nutr 65, 692S-697S.

14. Kirsten VR \& Wagner MB (2014) Salt taste sensitivity thresholds in adolescents: are there any relationships with body composition and blood pressure levels? Appetite 81, 89-92.

15. Cho H, Kim SM, Jeong SS, et al. (2016) Comparison of salt taste thresholds and salt usage behaviours between adults in Myanmar and Korea. Asia Pac J Clin Nutr 25, 879-884.

16. Michikawa T, Nishiwaki Y, Okamura T, et al. (2009) The taste of salt measured by a simple test and blood pressure in Japanese women and men. Hypertens Res 32, 399-403.

17. Kubota Y, Higashiyama A, Sugiyama D, et al. (2018) Association between impairment of salty taste recognition and masked hypertension based on home blood pressure in Japanese residents: the KOBE Study. Hypertens Res. 41, 756-762.

18. Imano H, Kitamura A, Sato S, et al. (2009) Trends for blood pressure and its contribution to stroke incidence in the middle-aged Japanese population: the Circulatory Risk in Communities Study (CIRCS). Stroke 40, 1571-1577.

19. Yamagishi K, Muraki I, Kubota Y, et al. (2019) The Circulatory Risk in Communities Study (CIRCS): among Japanese men and women living in communities. J Epidemiol 29, 83-91.

20. Nishimoto K, Hirota R, Egawa M, et al. (1996) Clinical evaluation of taste dysfunction using a salt-impregnated taste strip. ORL J Otorbinolaryngol Relat Spec 58, 258-261.

21. Maruyama C, Nakamori T, Nakanishi $\mathrm{Y}$, et al. (1988) Development and study of salt taste sensitivity test for evaluation of diet therapy. Japanese J Nutr Diet 46, 211-216.

22. Yoshinaka M, Ikebe K, Uota M, et al. (2016) Age and sex differences in the taste sensitivity of young adult, young-old and old-old Japanese. Geriatr Gerontol Int 16, 1281-1288.

23. Iso H, Shimamoto T, Naito Y, et al. (1998) Effects of a longterm hypertension control program on stroke incidence and prevalence in a rural community in Northeastern Japan. Stroke 29, 1510-1518.

24. Brinsden HC, He FJ, Jenner KH, et al. (2013) Surveys of the salt content in UK bread: progress made and further reductions possible. BMJ Open 3, e002936.

25. He FJ, Pombo-Rodrigues S \& Macgregor GA (2014) Salt reduction in England from 2003 to 2011: its relationship to blood pressure, stroke and ischaemic heart disease mortality. BMJ Open $\mathbf{4}$, e004549.

26. Kusaba T, Mori Y, Masami O, et al. (2009) Sodium restriction improves the gustatory threshold for salty taste in patients with chronic kidney disease. Kidney Int 76, 638-643. 